\title{
Erratum to: Elemental Composition of Mnemiopsis leidyi A. Agassiz 1865 and Its Implications for Nutrient Recycling in a Long Island Estuary
}

Marianne E. McNamara • Darcy J. Lonsdale •

Robert C. Aller

Published online: 6 September 2013

(C) Coastal and Estuarine Research Federation 2013

Erratum to: Estuaries and Coasts

DOI 10.1007/s12237-013-9636-x

The axis title for Beroe ovata in Fig. 2 should read B. ovata $\left(10^{6} \mathrm{~L}\right)^{-1}$. We regret the error.

The online version of the original article can be found at http://dx.doi.org/ 10.1007/s12237-013-9636-X.

M. E. McNamara • D. J. Lonsdale · R. C. Aller

School of Marine and Atmospheric Science, Stony Brook University,

Stony Brook, NY 11794-5000, USA

M. E. McNamara $(\bowtie)$

Biology Department, Suffolk County Community College, Selden, NY 11784, USA

e-mail:mcnamam@sunysuffolk.edu
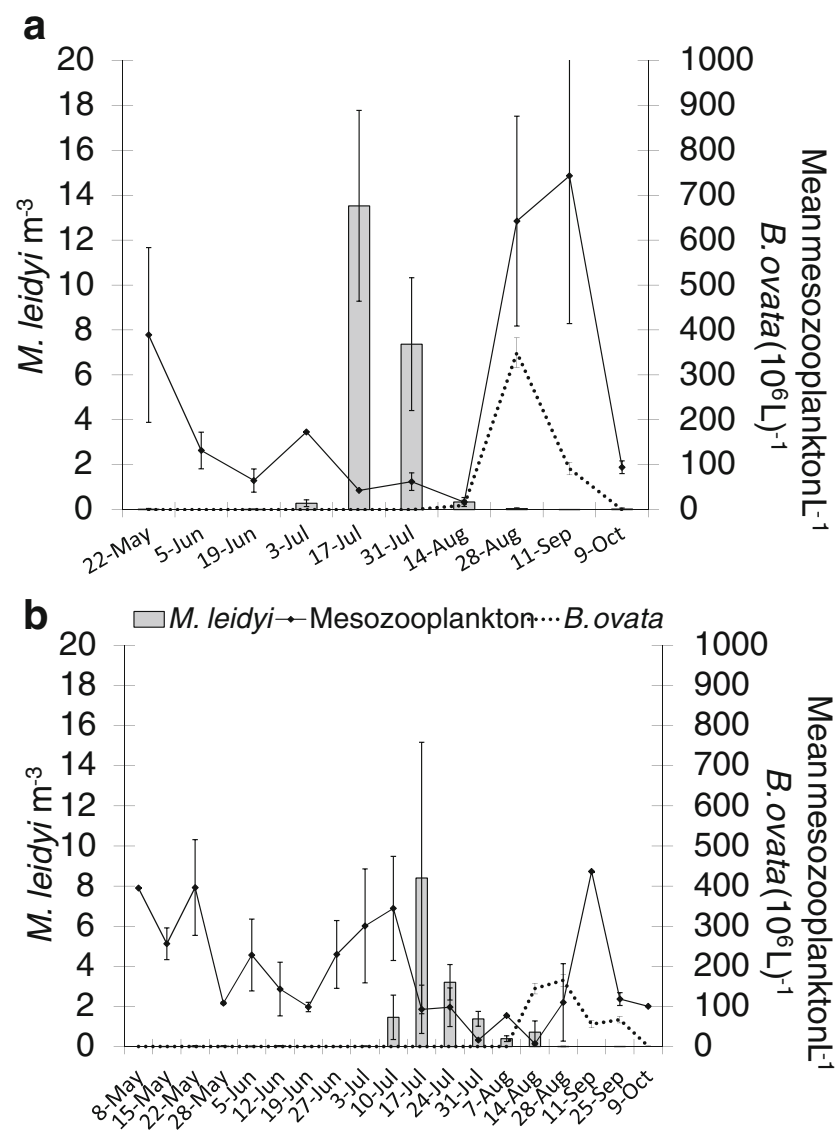

Fig. 2 Mean mesozooplankton ( \pm range), Beroe ovata ( $\pm \mathrm{SD})$, and $M$. leidyi $( \pm \mathrm{SD})$ abundance in Great South Bay at sampling sites M (a) and A (b), during 2008 